\title{
A Fenomenologia como Fundamentação para o Movimento Humano Significativo
}

\author{
Aguinaldo César Surdi* \\ Elenor Kunz ${ }^{* *}$
}

\begin{abstract}
Resumo: $O$ trabalho, teórico e qualitativo, investiga a argumentação que a fenomenologia proporciona para o entendimento do movimento humano como significativo. Usa como base o pensamento fenomenológico de Edmund Husserl e Merleau Ponty. A visão fenomenológica do movimento humano propõe que o sujeito seja o ator de seu movimento próprio e não apenas um objeto que recebe ordens para imitar padrões de movimento preestabelecidos. O movimento deve ser entendido como um diálogo entre homem e mundo. Manifesta-se como gesto criativo, com possibilidade de conhecer e transformar o mundo e deve orientar o trabalho na educação física, para que esta consiga recuperar seu real sentido no processo educacional.
\end{abstract}

Palavras-chave: Fenomenologia. Movimento. Conhecimento. Educação Física

\section{INTRODUÇÃO}

Do ponto de vista histórico, podemos considerar que a razão cientifica moderna teve seu início nos séculos XVI e XVII, principalmente, com Descartes e Francis Bacon, sua principal característica e sua ruptura com o pensamento medieval fundado sobre o dogmatismo cristão, ou seja, a escolástica que pregava a aceitação de dogmas e verdades estabelecidas para manter a ordem social. O marco inaugural da Razão Científica Moderna é o advento do Renas-cimento, no Século XVI, que estabelece a visão antropocêntrica contra o teocentrismo medieval e valoriza o indivíduo, a consciência, a subjetividade, a atividade crítica e a experiência objetiva como fonte de conhecimento.

\footnotetext{
* Professor do Departamento de Ciências Humanas e Sociais, Letras e Educação Física. Área de Educação Física. Universidade do Oeste de Santa Catarina. Videira. Santa Catarina. Brasil. E-mail: aguinaldosurdi@yahoo.com.br

** Professor Doutor do Departamento de Educação Física. Centro de Desportos. Universidade Federal de Santa Catarina. Florianópolis, SC, Brasil. E-mail: elenkunz@terra.com.br
} 
No Renascimento, desencadeia-se a revolução científica, com o surgimento de importantes teorias no campo da física e da astronomia com Galileu e Copérnico, entre outros. Surgem os primeiros germens da chamada Modernidade que se caracteriza por uma radicalmente nova visão de mundo que se funda sobre a ideia de progresso através do desenvolvimento da ciência e da Razão Antropocêntrica, isto é, que se opõe à Razão Teocêntrica, colocando o Homem no lugar de Deus.

Durante os séculos seguintes, o Mundo Moderno vai surgindo a partir das ruínas do mundo antigo e medieval e, com ele, as promessas de igualdade, fraternidade, liberdade e prosperidade para todos que irão caracterizar a Revolução Francesa quase ao final do Século XVIII. Contudo, a racionalidade moderna que prometia a redenção da humanidade carrega consigo o ônus do desmoronamento da razão e com ela a crise do sujeito. Esta razão, ligada à ciência e à tecnologia, converteu-se em instrumento de desumanização. Japiassu (1991) declara que a racionalidade científica se transformou em instância cultural reconhecida por todos. Uma vez instaurada como saber dominante, a ciência, por ser considerada isenta de pressupostos ideológicos e de juízos de valor, transforma-se numa espécie de emblema para as diretrizes do poder político. E, em nome da ciência e da tecnologia, se estabelecem novas formas de desigualdades sociais e econômicas e novas formas de exploração do homem pelo homem, desta vez em nome do próprio Homem e de sua liberdade individual.

Segundo Crema (1989), a visão moderna de mundo foi reforçada com o surgimento do paradigma cartesiano-newtoniano, no Século XVII, que interpreta o mundo como uma grande máquina, privilegiando os caracteres matemáticos, como uma crise de fragmentação, atomizacão e desvinculação. O homem se encontra esfacelado em seu pensar e agir, vivendo de forma parcializada. Comenta, ainda, que, como consequência, o próprio mundo é caracterizado pelo fracionamento, em territórios e nacionalidades, em constante estado de guerra. Esta visão especializada que privilegia um conhecimento também especializado, conduz-nos ao caos, deixando a espécie humana em sérias enrascadas, à beira de um abismo.

Movimento, Porto Alegre, v. 15, n. 02, p. 187-210, abril/junho de 2009. 
Dentro deste contexto geral da chamada Modernidade, situa-se a questão do movimento humano e de seus aspectos significativos que podem ser estudados sob ópticas muito diferentes. Contudo, a concepção científica do mundo que privilegia a técnica mostra que a principal importância do movimento humano é obedecer a uma ordem externa, baseada em leis, com intenção de desempenho. Esta construção da ciência em modelos quantitativos nos traz uma visão parcializada do entendimento do movimento humano.

Santin (1992) contesta essa visão moderna, perguntado como podemos pesquisar a vida ou a fenomenologia do vivo? Como decifrar a sua mensagem? Salienta que o modelo moderno de produção do conhecimento praticado pelos métodos científicos do enfrentamento entre sujeito e objeto e a leitura matemática não podem, de forma alguma decifrar a linguagem da corporeidade. Para o autor, esse conhecimento deve ser feito de forma direta, sem mediações das leis e regras da racionalidade científica. A racionalização construída pelo desenvolvimento científico dá forma ao movimento humano. Segundo Kunz (1995), isto é consequência do predomínio de uma interpretação técnica do movimento humano, baseado nos métodos das ciências exatas.

Nas aulas de educação física, podemos observar claramente o predomínio de conteúdos esportivos com objetivos de seleção e formação do atleta. Tudo passa a girar em torno do corpo em movimento, organizado e regrado pelas leis da física e da mecânica. O movimento passa a ser matéria-prima de qualquer iniciação esportiva. Ele não é desenvolvido a partir das potencialidades e limites do corpo, mas, em função da modalidade esportiva praticada. $\mathrm{O}$ corpo, neste sentido, produz movimentos mecanicamente automatizados.

O ser humano perde seu poder de decisão e reflexão sobre seu se-movimentar, que o torna humano e criativo. Dentro deste mesmo ponto de vista, Bracht (1999) enfatiza que se tratar do movimento humano a partir da ciência clássica introduz-se um reducionismo ao seu entendimento que deveria ser evitado. Para o autor, esta teorização teria que ultrapassar o próprio teorizar científico. A teorização a que se propõe as ciências tradicionais não atende às necessidades que a

Movimento, Porto Alegre, v. 15, n. 02, p. 187-210, abril/junho de 2009. 
educação física precisa ter sobre o movimento humano com intenção pedagógica. Teríamos de englobar o biológico, o psicológico, o social, mas, também, o ético e o estético, ou seja, numa perspectiva globalizada, que atenda uma razão teórica, prática e a dimensão da subjetividade. Aqui, podemos entender que através do conhecimento destas inúmeras dimensões do movimento humano, compreendemos sua globalidade.

Baseado nesta fundamentação prévia, foi formulado como problema central dessa pesquisa teórica a seguinte questão: Qual a argumentação teórica fornecida pela fenomenologia para que o movimento humano seja compreendido e entendido como significativo e intencional? Foi utilizado como suporte teórico à fenomenologia, principalmente aquela desenvolvida por Edmund Husserl e Merleau-Ponty. Queremos, assim, analisar os aspectos qualitativos do movimento humano, mostrando que a subjetividade e a intersubjetividade são fundamentais para ampliar, de forma significativa, o entendimento do movimento humano. Sendo assim, a fenomenologia, por buscar voltar às coisas mesmas, isto é, fugir das influências da racionalidade científica sobre o conhecimento e propondo uma investigação sistemática da consciência e de seus objetos, se torna um importante fundamento filosófico para argumentar esta discussão. Filosófico, porque, conforme Kunz (1991), as investigações sobre o movimento humano, atualmente, não abrangem toda a sua complexidade e realidade. Para complementar, Santin (1987, p. 55) enfatiza que "a filosofia através de um trabalho genealógico da crise, busca reencontrar o caminho de restabelecimento de um equilíbrio perdido". Igualmente, Vaz (1995), comenta que temos de pensar os temas da educação física com base na filo-sofia. É através da filosofia e do seu processo de filosofar que transcende os limites e as possibilidades do pensamento, alcançando suas riquezas.

\section{A FenOMENOLOGiA}

A fenomenologia como corrente filosófica foi fundada por E. Husserl, na Alemanha do fim do Século XIX e começo do Século XX. Husserl pretendia estabelecer um método de fundamentação da ciência, constituindo a filosofia como uma ciência rigorosa que

Movimento, Porto Alegre, v. 15, n. 02, p. 187-210, abril/junho de 2009. 
deveria acompanhar o método científico. Podemos dizer que a fenomenologia é formada por duas partes, ambas de origem grega. Primeiro vem a palavra "Fenômeno" que significa "aquilo que se mostra" e não simplesmente aquilo que "aparece ou parece". Em segundo, vem a palavra "logia" que, para os gregos, recebia muitos significados, para melhor entender, vamos utilizá-la como pensamento ou como capacidade para refletir. Desta forma, Bello (2006, p. 18) comenta que a fenomenologia pode ser entendida "[...] como reflexão sobre um fenômeno ou sobre aquilo que se mostra. O nosso problema é: o que é que se mostra e como se mostra". Ao dizer que as coisas se mostram, queremos dizer que ela se mostra para nós, ao ser humano.

O projeto fenomenológico baseia-se no movimento de "voltar às coisas mesmas", isto é, aos fenômenos, que é aquilo que aparece a consciência de forma intencional (JAPIASSU; MARCONDES, 1996). Neste sentido, ela contrapõe à visão positivista do século XIX que é presa à concepção objetiva de mundo, a um conhecimento científico neutro cada vez mais distante do homem e de sua subjetividade e propõe a humanização da ciência baseada na ruptura do dualismo psicofísico por uma relação inseparável entre corpo - mente e homem - mundo.

$\mathrm{Na}$ fenomenologia, todas as coisas que se mostram a nós tratamos como fenômenos. Segundo Bello (2006), o fato de se mostrarem não interessa tanto, mas sim, compreender o que são, isto é, o seu sentido e/ou significado. Para a autora, o grande problema da filosofia hoje em dia, é buscar o sentido das coisas, tanto de ordem física, quanto cultural, religiosa etc, das coisas que se mostram para nós. Salienta ainda que para compreender o sentido dos fenômenos, devemos fazer uma série de operações, pois nem sempre conseguimos compreender tudo imediatamente.

A descrição fenomenológica, segundo Husserl apud MerleauPonty (1971), entende a fenomenologia como sendo uma psicologia descritiva ou ainda que oportuniza um retorno às coisas mesmas. Enfatiza que isto é o desmentido da ciência. Tudo o que sabemos sobre a ciência sabemos a partir de nossa vida pessoal, através de nossas experiências no mundo. Neste caso, enfatiza que os símbolos

Movimento, Porto Alegre, v. 15, n. 02, p. 187-210, abril/junho de 2009. 
da ciência e seu rigor na tentativa de explicar o mundo, não teriam nenhum sentido. A ciência vem depois da experiência humana no mundo vivido. Esta descrição dos fenômenos do mundo em que vivemos é buscar entender o fenômeno exatamente como ele se apresenta em nossa consciência.

Neste sentido, Husserl (1991) propõe estabelecer uma base segura, liberta de pressuposições, para todas as ciências e, de modo especial, para a filosofia. A suprema fonte legítima de todas as afirmações racionais é a visão, ou também, como ele se exprime a consciência doadora de sentido. Devemos, neste sentido, avançar para as próprias coisas. Esta é a regra primeira e fundamental da fenomenologia. Por "coisas", podemos entender que é aquilo que nos é dado, aquilo que vemos ante nossa consciência. Este dado chama-se fenômeno, no sentido de que aparece diante da consciência. A palavra não significa que algo desconhecido se encontre detrás do fenômeno. A fenomenologia não se ocupa disso, só visa ao dado, sem querer decidir se este dado é uma realidade ou uma aparência. Independente do que houver, a coisa está aí, é dada. O autor reforça esta afirmação dizendo que este movimento de retorno é distintamente diferente do idealista. A exigência desse movimento é uma descrição pura, sem nenhuma influência de análises reflexivas ou das explicações científicas. Busca descrever o que realmente o fenômeno é, ou seja, sua essência.

Para explicar melhor a essência, ela busca esclarecer a questão o que é o que é? E logo depois se remete para outra questão, o que se quer dizer? Há essência em tudo o que percebemos. O mundo é aquilo que percebemos. Segundo Merleau-Ponty $(1971$, p. 13) “[...] buscar a essência do mundo, não é buscar o que ele é em ideia, uma vez que o reduzimos a tema de discurso, é buscar o que ele é de fato para nós antes de qualquer tematização". Com a minha experiência vivida, eu vejo o mundo e desta forma eu percebo um mundo. Eu sou desta forma direcionado ao mundo e da mesma maneira o mundo é direcionado a mim. Percepção que para Merleau-Ponty (1971, p. 8) "[...] não é uma ciência do mundo, não é mesmo um ato, uma tomada de posição deliberada, é o fundo sobre o qual todos os atos se destacam

Movimento, Porto Alegre, v. 15, n. 02, p. 187-210, abril/junho de 2009. 
e ela está pressuposta por eles." Portanto, podemos dizer que as essências são o que dão sentido/significado às coisas ou fenômenos e que nós percebemos através de nossa consciência intencional.

Sobre a questão da Intencionalidade, Husserl (1991) comenta que a consciência é um ato intencional e sua essência é a intencionalidade, ou o ato de visar às coisas, dando-lhe significado. $\mathrm{O}$ mundo ou a realidade é o correlato intencional da consciência. Podemos dizer que a percepção é uma unidade interna entre o ato e o correlato e entre o perceber e o percebido. Perceber é o ato intencional da consciência. A intencionalidade é um caminho que faz a consciência se voltar para o mundo e vice-versa. Desta forma, a intencionalidade é a característica definidora da consciência, na medida em que está necessariamente voltada para o objeto. "A consciência só é consciência a partir de sua relação com o objeto, com um mundo já constituído que a precede. Este mundo só adquire sentido enquanto objeto da consciência" (JAPIASSU; MARCONDES 1996, p. 145). Segundo Dartigues (2003, p.18), o princípio da intencionalidade faz com que a consciência, sempre estando dirigida a um objeto, forneça a noção de sentido ou significado. Desta forma "[...] o objeto só pode ser definido em sua relação com a consciência, ele é sempre objetopara-um-sujeito".

Tanto Husserl como Merleau-Ponty, concordam que para conhecermos as coisas e o mundo a experiência é primordial. Sem ela, a ciência seria impossível. Por este motivo, através deste retorno às coisas mesmas é que podemos resgatar o valor da experiência eliminado pelos empiristas e intelectualistas. Estes preferem o valor da razão que por si só seria capaz de conhecer o mundo, as coisas e a si mesmo sem ter nenhum contato direto com o mundo. Defendem que este tipo de conhecimento não fornece nenhum saber evidente, necessário e universal.

O que é de interesse para a fenomenologia não é o mundo que existe, mas sim, o modo como o conhecimento do mundo se dá e se realiza para cada pessoa. Ela requer a suspensão das atitudes, crenças, preconceitos, teorias, colocando em suspenso o conhecimento das

Movimento, Porto Alegre, v. 15, n. 02, p. 187-210, abril/junho de 2009. 
coisas do mundo exterior a fim de se concentrar na pessoa, exclusivamente, na experiência em foco, tentando fazer a sua descrição e deixando, também, o fenômeno falar por si mesmo. A fenomenologia deve praticar não a dúvida cartesiana, mas, a denominada epoché que significa descrever os fenômenos presentes na consciência quando são colocados entre parênteses, isto é, depurados de sua carga de preconceitos histórico-culturais. A fenomenologia é antes o modo como o conhecimento do mundo acontece na visão que o indivíduo tem do mundo. Desta forma, a intencionalidade da consciência é que leva esta consciência para o fenômeno e da mesma forma o fenômeno é atraído por esta consciência, na qual ambos são percebidos mutuamente. Merleau-Ponty (1971) comenta que a intencionalidade pode ser considerada como a principal descoberta da fenomenologia.

Falamos muito sobre compreender o sentido das coisas, mas podemos compreender o sentido das coisas? Para quê compreender o sentido das coisas? Husserl (2001) diz que podemos e devemos compreender o sentido das coisas, para que nossa experiência quotidiana possa orientar nossas vivências. Salienta que existem algumas coisas cujo sentido podemos identificar de forma imediata, enquanto em outras temos mais dificuldade. Reforça que, o sentido das coisas, nós intuímos. A intuição das essências é o primeiro passo do caminho que revela ser possível captar o sentido.

Sobre a questão de ter consciência das vivências, Husserl (1986) diz que o ser humano tem a capacidade de ter consciência dos seus atos enquanto ele está vivendo estes atos, enquanto está realizando estes atos. Este processo acontece através da percepção das coisas que segundo Bello (2006), é o resultado que faz com que o ser humano possa dar-se conta. Este dar-se conta é a consciência de algo, por exemplo, a consciência de tocar em alguma coisa. Desta forma, podemos dizer que ver e tocar são vivências e, dessa forma, podem ser registradas por nós e delas termos consciência. "Ter consciência dos atos que são por nós registrados são vivências”. (Bello, 2006, p. 32)

Para Sokolowski (2004), esta atividade de dar conta é o significado do termo fenomenologia. Esta atividade de dar conta proporciona um logos, de vários fenômenos e dos vários modos em que as coisas

Movimento, Porto Alegre, v. 15, n. 02, p. 187-210, abril/junho de 2009. 
podem aparecer. Podemos explorar todos os fenômenos, quando perce-bemos a intencionalidade de nossa consciência em direção ao fenômeno.

Segundo Merleau-Ponty (1971), a fenomenologia busca compreender o homem e o mundo a partir de sua facticidade. Entendemos daquilo que não e necessário, mas simplesmente é. A consciência aprende-se a si mesmo como fato. Fato de que as coisas estão ai, simplesmente como são, sem necessidade nem possibilidade de ser de outra forma. Complementa que a fenomenologia "é uma filosofia segundo o qual o mundo está sempre aí antes da reflexão, como uma presença inalienável, e cujo esforço está em reencontrar este contato ingênuo com o mundo para lhe dar enfim um status filosófico (p. 5)". O autor enfatiza também que a fenomenologia é um movimento de retorno ao mundo pré-reflexivo, para buscar entendê-lo antes de qualquer forma de análise, interpretação ou explicação.

Merleau-Ponty (1971) critica a ciência ao dizer que todo o universo da ciência é construído sobre o mundo vivido. Mundo esse que deve ser nossa primeira experiência e a ciência, a segunda. "A ciência não tem e não terá jamais o mesmo sentido de ser que o mundo percebido, pela simples razão de que ela é ou sua determinação ou explicação" (p. 6). Podemos enfatizar que a tarefa da fenomenologia é a de desvelar o mundo vivido antes de ser significado. Mundo este que conta nossas histórias, onde fizemos nossas relações e tomamos nossas decisões.

O mundo fenomenológico, para Merleau-Ponty (1971, p. 17):

[...] é, não o do ser puro, mas o sentido que transcende à intersecção de minhas experiências com as do outro, pela engrenagem de umas sobre as outras, ele é pois inseparável da subjetividade e da intersubjetividade que fazem sua a unidade pela retomada de minhas experiências passadas em minhas experiências presentes, da experiências do outro na minha. [...] O mundo fenomenológico não é a explicação de um ser preliminar, mas o fundamento do ser, a filosofia não é o reflexo de uma verdade prévia, mas como a arte, ela é a realização de uma verdade.

Movimento, Porto Alegre, v. 15, n. 02, p. 187-210, abril/junho de 2009. 
O Mundo pode ser assim compreendido como o primeiro ato ou o ato mesmo. Ato este que só pode ser feito num mundo inacabado, para que nós possamos refletir sobre esse mundo a nosso modo. Neste sentido, Merleau-Ponty (1971) comenta que temos que reaprender a ver o mundo. Ver o mundo sem as predeterminações constituídas, consolidadas e padronizadas pelo conhecimento científico. Nossa consciência deve ser direcionada a uma experiência que busque o sentido do mundo em seu estado nascente e irrefletido.

\section{MUNDO DA VIDA E MUNDO DA CIÊNCIA}

A ciência moderna e sua consequente forma de quantificar a realidade se tornaram alvo de muitas críticas por ignorar inúmeras questões significativas que fazem parte do mundo da vida. O mundo em que vivemos produz uma gama de possibilidades e diversidades de sons, imagens, árvores, paisagens, rios, lagos e muito mais, que são entendidas como qualidades secundárias pela ciência. Estas qualidades fazem parte do mundo irreal, enquanto que o mundo real é fornecido pelo conhecimento científico da natureza. Desta forma, o mundo da ciência é o verdadeiro enquanto que aquele que vivenciamos de forma direta é ilusório e insignificante.

Este mundo da vida ou mundo vivido, que é a tradução da palavra alemã (Lebenswelt), é um termo utilizado por Husserl para designar o mundo da experiência humana que é considerado antes de qualquer tematização conceitual. Segundo Japiassu e Marcondes (1996), o mundo da vida é o que aceitamos como dado, como pressuposto e que constitui nossa experiência cotidiana. "Trata-se do real em seu sentido pré-teórico e pré-reflexivo" (p. 190). Husserl (2001) comenta que a reflexão deve começar por retornar à descrição do mundo vivido. Neste sentido, Merleau-Ponty (1971) procura encontrar um fundamento anterior ao mundo pensado. Na nossa experiência do dia-adia, predominam os atos inconscientes e não os conscientes. Segundo Carmo (2004), é este o motivo pelo qual Merleau-Ponty emprega em suas obras termos como retornar, reencontrar, recolocar, restituir e outros que procuram mostrar a importância de buscar a experiência pré-consciente.

Movimento, Porto Alegre, v. 15, n. 02, p. 187-210, abril/junho de 2009. 
Como exemplo ilustrador do entendimento do conceito de préreflexivo, Carmo (2004) comenta sobre a experiência infantil. A criança, antes de pensar, ela percebe o mundo a sua volta. Ela assim percebe exatamente este mundo antes de ser refletido pelo nosso pensamento. Salienta ainda que este processo que se inicia no mundo anterior a reflexão (mundo pré-reflexivo) e que fornece os argumentos para que possamos entender o processo de conscientização. Todas as formas de pré-conceitos e pré-juízos devem ser eliminados para que possamos começar a refletir sobre as coisas.

O conhecimento científico como critério de verdade nos fornece, de forma parcializada, um modelo padrão de entender as coisas. $\mathrm{O}$ que nos aparenta ser uma mesa, segundo Sokolowski (2004), para a ciência "[...] é na verdade um conglomerado de átomos, campos de força e espaços vazios. Átomos e moléculas, as forças, os campos e as leis descritas pela ciência são considerados a verdadeira realidade das coisas". Nossas percepções, desejos e necessidades que estão relacionadas como o mundo em que vivemos são meros estímulos de nossas mentes que chegam através de nossos sentidos, e são biologicamente e automaticamente transmitidos aos objetos. Nossa experiência no mundo da ciência não vale nada. A cultura científica produziu um poder ideológico nas pessoas que pensam que a verdade das coisas só pode ser descrita pela ciência. Mesmo questões puramente humanas como consciência, raciocínio e linguagem devem ser reduzidos em princípios para serem entendidas pelas ciências correspondentes desta área.

Podemos perceber que existem dois mundos distintos. O mundo no qual vivemos é o mundo descrito pela ciência matemática que entende a realidade como verdades objetivas, e o mundo da vida que é entendido como sendo puramente subjetivo e como mero fenômeno. Para Sokolowski (2004), o mundo da vida era o único que existia. Isto quer dizer que ele não surgiu antes da ciência, mas foi dominado por ela. A ciência pré-moderna surgiu com a intenção de simplificar a realidade através da descrição exata e de definições das coisas que percebemos no mundo. $\mathrm{O}$ autor salienta que as ciências matemáticas têm suas origens no mundo vivido pelas pessoas. "Elas são fundadas no

Movimento, Porto Alegre, v. 15, n. 02, p. 187-210, abril/junho de 2009. 
mundo da vida" (p. 158). Neste sentido, Dartigues (2003) também comenta sobre um divórcio entre o mundo da ciência e o mundo da vida. O mundo da ciência, em função do método rigoroso, está diluindo seu alcance e seu sentido, e acaba se fechando cada vez mais em si mesma. O mundo da vida busca uma racionalidade não encontrável.

A ciência moderna surge para interpretar o mundo em que vivemos. Mas nós podemos interpretar o mundo através de nossa subjetividade e tornar esta interpretação válida e fidedigna. Mas a ciência com seu método simplificador transformou as experiências que temos diretamente das coisas em objetos matemáticos. Desenvolveram uma forma de identificação da realidade passível de ser explicada numericamente. Para Sokolowski (2004), parece que a ciência descobriu um novo mundo, mas, conforme a fenomenologia, o que ela fez foi criar um novo método ao mundo ordinário.

As promessas de que a razão fundada na ciência e consequentemente na descoberta e na dominação da natureza, iria promover uma revolução na vida do homem em função do bem comum não foram realizadas. As reformas pretendidas em toda a humanidade como na filosofia da educação, nos aspectos sociais e políticos ainda estão para serem atendidos. Os fins que se destinam às descobertas científicas são coisas que nem os próprios cientistas sabem, em função da fragilidade e da fragmentação de seus métodos.

Para Sokolowski (2004), nosso mundo é o mundo da vida, aquele que nos parece e trata de nossas experiências básicas e possui formas próprias de verdade e verificação. Nós não poderíamos viver num mundo totalmente projetado pela ciência. Ela pode apenas complementar esta verdade constituída no mundo da vida. Desta forma, as ciências são derivadas do mundo vivido e do que existe nele, este mundo é a base para a ciência. A fenomenologia deseja que a ciência reivindique um lugar no mundo da vida, mas jamais pode substituí-lo. Para o autor, a fenomenologia reconhece a ciência matemática e seu valor, mas nunca a supervaloriza, pois ela é construída sobre as coisas que são dadas para nós no modo pré-científico.

Podemos dizer que as exclusões e limitações que se pretende a ciência nos aspectos culturais, subjetivos e práticos, ela se torna

Movimento, Porto Alegre, v. 15, n. 02, p. 187-210, abril/junho de 2009. 
sem vida. Ela ignora nossas mais íntimas e verdadeiras expressões de felicidade e alegria. Nossas percepções do tempo, do ato de brincar e de se divertir perante a natureza, para a ciência, isto, não valem de nada. Estas reais expressões humanas e com certeza as mais significantes que podemos ter a ciência não consegue entender. $\mathrm{O}$ mundo da ciência "é um sistema material, real e fechado, é um mundo inabitado e inabitável" (DARTIGUES, 2003, p. 78).

Para a fenomenologia, a objetividade da ciência não deve ser renunciada, mas sim integrada ao mundo da vida. Mas, como podemos perceber o mundo vivido, como ele nos aparece? Como o mundo vivido é descrito no plano das ideias, a autorreflexão se torna o próprio objeto do pensamento. Segundo Merleau-Ponty (1971), o mundo exterior é colocado entre parênteses, à reflexão, busca um recuo do mundo, mas nunca se retira definitivamente, ou ainda como diz o autor "distende os fios intencionais que a ligam ao mundo"

As coisas ideais são os principais fundamentos das ciências modernas. Para Sokolowski (2004), estes objetos idealizados pela ciência jamais seriam experienciados no mundo da vida, em função da nossa percepção e imaginação. A ciência, usando seus métodos, transforma estes objetos concretos que experienciamos em idealizados e nós começamos a relacioná-los. Desta forma, como acontece hoje, os objetos idealizados tornam-se cópias perfeitas daquilo que percebemos, por serem mais exatas e consequentemente mais reais. Finaliza Sokolowski (2004, p. 160) “[...] que as coisas que percebemos parecem ser só cópias imprecisas do padrão perfeito“"

Estes objetos idealizados, como são perfeitos, são iguais em todos os lugares que se encontrem. Desta forma, entram em contraste com as inúmeras variações que existem em nossas percepções da realidade. Pelo fato da ciência excluir as variações que se passam por todas as coisas no mundo, ela sempre será limitada e cerva do mundo da vida. Os padrões desenvolvidos por ela estão longe de levar em consideração as diferenças individuais. A diferença não é significativa para o mundo da ciência. "Nós geometrizamos um objeto que foi uma vez uma coisa percebida no mundo" (SOKOLOWSKI, 2004, p. 161).

Movimento, Porto Alegre, v. 15, n. 02, p. 187-210, abril/junho de 2009. 
Toda esta experiência vivida que acontece no mundo da vida é, para Merleau-Ponty (1971), corporal. Ele recupera o corpo que foi esquecido pela filosofia clássica e o coloca como o fundamento de todo o conhecimento. Este corpo de que fala Merleau-Ponty, não é aquele corpo projetado e entendido pela ciência, através de relações mecânicas de estímulo e resposta, mas é um ser animado por relações imaginárias com o mundo. O corpo é a natureza e a própria cultura por fornecer ao homem a oportunidade de viver, criar e desvendar o mundo. Ele não é algo passível como pensamos, mas sim é o que nos proporciona colocar-nos em contato com os outros e com o mundo. Podemos observar que a percepção original do mundo se dá através da corporeidade.

\section{CORPOREIDADE, EXPRESSIVIDADE E MOVIMENTO HUMANO}

O corpo entendido pela ciência moderna é uma massa corpórea feita para obedecer a quem o mandar. Podemos perceber esta relação em muitos postos de trabalho, em que depende do porte atlético do corpo e de sua força física para garantir um emprego. Mesmo sabendo o empregador que o esforço exigido no trabalho é maior do que a capacidade humana pode suportar, ou ainda, como cobaia para testes físicos ou laborais com a intenção de melhoramentos científicos. Para finalizar, podemos citar também as atividades do dia-a-dia, em que as formas de movimentos, sejam no lazer, nas práticas esportivas e, até mesmo nas escolas, nos são dadas prontas, como se todos nós fôssemos iguais.

A ciência, por intermédio dos meios de comunicação, pensa por nós e nos ordena ideologicamente a fazer ou a copiar tal atividade. Desta forma, podemos dizer que esta ciência e seus métodos e modelos teóricos, lidam com os corpos sem vida. Sabem lidar com as estatísticas e as diferenças percentuais dos acontecimentos, mas nunca poderá entender o significado de um corpo vivo, que se expressa e se comunica com o mundo através do seu movimento. Corpo este que não pode ser entendido pela matemática, mas sim pelo silêncio de poder ouvir a sua fala e entender o que ele deseja. Este desejo significa entender a si mesmo como um ser-no-mundo.

Movimento, Porto Alegre, v. 15, n. 02, p. 187-210, abril/junho de 2009. 
Esta ideia de entender o corpo com vida e possuidor de sentimento, está muito além de pensarmos como um mero e simples objeto. O corpo agora é o que eu sou, é o que me faz ser humano. Este corpo sonha, brinca, trabalha e tudo o mais, para caracterizar minhas experiências no mundo. É este corpo que revela nosso potencial de criação e expressão frente ao mundo que percebo. Esta é a real maneira de sermos humanos. A corporeidade é isto, uma unidade corporal indivisível do se-movimentar humano, que proporciona a construção do mundo da vida com todas as possibilidades e dimensões.

Baseado nesta ideia, a fenomenológica entende expressividade e corporeidade como sendo sinônimo. Segundo Merleau Ponty (1971), nossa forma de se expressar e de se comunicar com o mundo acontecem através do nosso corpo. É na experiência com o nosso corpo, com o outro e com o mundo, que se entende de modo organizado e espontâneo os fenômenos. É em nosso corpo que a existência se realiza. A expressão, pode-se dizer, é um elo entre o sensível e o significado.

Nas relações entre o eu, o outro e o mundo, o significado das coisas aparecem. O mundo está sempre por fazer-se. A ligação do meu corpo com os fenômenos do mundo através da experiência proporciona a percepção real de todas as coisas. Esta percepção está baseada na minha vivência no e/ou com o mundo. Nosso corpo possui o poder da expressão e do movimento, que transforma nossas intenções em atos afetivos. Desta forma, nosso corpo deve ser entendido como um todo em que pensamento, palavra e movimento existem um para o outro, não tem possibilidade de existir um sem o outro. Nossos pensamentos ganham vida pelos movimentos, que são corporificados pela palavra e pela fala. Existe, desta forma, uma interdependência entre a palavra e o ato intencional. Os atos intencionais só podem ser expressos pela palavra e as palavras só recebem significação pelos atos intencionais.

Merleau-Ponty (1971) entende o movimento humano como sendo uma reflexão, que nos remeteria a uma regra pré-reflexiva pela qual a subjetividade e a objetividade seriam constituintes. As sensações humanas seriam localizadas no corpo. Este seria um campo possuidor da capacidade de sentir e de ser ao mesmo tempo sujeito e

Movimento, Porto Alegre, v. 15, n. 02, p. 187-210, abril/junho de 2009. 
objeto. O corpo, neste sentido, deve ser entendido como corpo próprio e, desta forma, como corporeidade. A corporeidade só pode ser compreendida como vivência humana que pretende fazer com que o mundo apareça para nós através de nossa consciência. O corpo, no dizer de Merleau-Ponty (1971), tornou-se o sujeito da percepção.

Podemos perceber o sentido de unidade entre as dimensões da expressividade e da corporeidade. A expressão é a operação da intencionalidade. No conceito de expressão, o sensível possui um sentido imanente, ou seja, o sentido habita o objeto. A expressão se realiza pela união natural de momentos que se comunicam interiormente em função do tempo. Sobre a questão da unidade, Merleau Ponty (1971) comenta o seguinte:

[...] só aprendemos a unidade de nosso corpo na unidade da coisa, e é a partir das coisas que nossas mãos, nossos olhos, todos os nossos órgãos dos sentidos nos aparecem como tantos instrumentos substituíveis. O corpo por ele mesmo, o corpo em repouso, é apenas uma massa obscura, e nós o percebemos como um ser preciso e identificável justamente quando ele se move em direção a alguma coisa.

O corpo se caracteriza pela sua possibilidade de movimento. Este corpo entendido como sendo corpo-sujeito, movimenta-se como uma intencionalidade que percebe as coisas vivendo-as. Este movimento vivo e livre, podemos dizer que é um ato expressivo, significativo e único. A expressão só pode ser realizada através do nosso corpo. Ela tem a capacidade de revelar o sentido de nossas experiências puras.

No entendimento da corporeidade, Santin (2005, p. 103) comenta que ela deve ser confundida como uma organização tanto de ordem material como cultural. Desta forma, podemos falar em "corporeidade social, doutrinal, jurídica, profissional e etc". O autor defende a ideia de que tanto corporeidade como corpo devem ser entendidos como tendo o mesmo sentido. Esta ideia deve ser baseada no entendimento do homem como um ser corporal, conforme o pensamento de Merleau-Ponty (1971). Merleau-Ponty fala do "ser corpo" como

Movimento, Porto Alegre, v. 15, n. 02, p. 187-210, abril/junho de 2009. 
algo real e existencial do ser humano. A corporeidade, desta forma, deve ir além da ideia abstrata do corpo e constituir o corpo, que é individual, indivisível e inalienável. A expressividade do corpo é como forma real e espontânea de vivência e demonstra que o homem vive o corpo e o mundo simultaneamente como uma unidade inseparável.

A corporeidade é a realidade humana que se constrói a cada momento no mundo. O homem é a sua corporeidade, uma forma única de viver a realidade corporalmente. Desta forma, ele é movimento criativo, que tem possibilidades ilimitadas de vivências que produzem gestos e expressões também ilimitados que tornam a relação com o mundo significativa e cheia de sentido. A presença do homem no mundo pode ser entendida através da sua corporeidade.

Esta corporeidade está ligada às intenções internas do homem. Com isto, devemos fugir do entendimento puramente material e limitado do homem corporal. Limitação esta que faz do homem um mero instrumento com objetivos externos e conflitantes aos seus desejos e capacidades que o tornam dono de si mesmo. O movimento criativo é sempre novo, é como um gesto que quando se expressa criativamente fala e se comunica com os outros e com o mundo.

As intenções humanas proporcionam uma vivência mais direta e mais criativa da realidade. Esta experiência direta do mundo vivido é onde deve surgir a nossa capacidade para conceituar o mundo e buscar entendê-lo de forma racional. Racionalidade esta criada por nós e não oferecida pronta pela linguagem científica. Desta forma, o movimento humano deve ser direcionado ao mundo sem restrições padronizadas. O direcionamento para o mundo vivido deve ser enfatizado como algo sempre novo que se constrói sempre.

A expressão corporal deve ser um espaço criativo. Ela se apresenta como sendo uma proposta de trabalhar com o movimento humano de tal forma que procura estabelecer uma relação reflexiva com o corpo. Para Schwengber (2005), os eixos conceituais que se explicitam com a expressão corporal são a inventividade, a espontaneidade, a sensibilidade, a liberdade corporal e a criação. A expressão pode ser entendida ainda como uma prática pedagógica que trabalha o "movimento como arte - arte (do movimento), num elo entre técnica e criatividade" (SCHWENGBER, 2005, p. 192-193).

Movimento, Porto Alegre, v. 15, n. 02, p. 187-210, abril/junho de 2009. 
Esta prática pedagógica que é a expressão corporal valoriza toda a possibilidade de inventividade do movimento. Entende o movimento como sendo possuidor de inúmeras interpretações e torna todos os sujeitos especiais por ser possível cada um ter sua individualidade nas diversas formas de realizar movimentos. Mostra que as pessoas estão vivas e são capazes de criar, não apenas imitando formas prontas de movimento. "Expressar-se corporalmente supões um trabalho de indivíduo sobre si, um jogo entre interiorização e exteriorização, numa produção de significantes" (SCHWENGBER, 2005, p. 193). Compreende, desta forma, a dinamicidade, de modo unitário de fatores como corpo, prazer, afetividade, tanto individuais como sociais. Ela é a própria linguagem corporal, que se torna consciente das reais possibilidades que possui e, desta forma, abre as portas para o ser humano se comunicar com o mundo. Para que todos tenham consciência dos seus atos através da realização dos seus movimentos como gestos significativos.

O gesto para Merleau-Ponty (1971), nunca é dado, mas sim compreendido. Esta compreensão está ligada ao outro, esta reciprocidade das intenções tanto do meu gesto quanto do outro se confundem. Sobre o sentido e o direcionamento do gesto, Merleau-Ponty (1971) comenta:

\footnotetext{
O gesto do qual sou o testemunha designa minuciosamente um objeto intencional. Este objeto torna-se atual e ele é compreendido inteiramente quando os poderes de meu corpo se ajustam a ele e o recobrem. O gesto está diante de mim como uma pergunta, ele me indica alguns pontos sensíveis do mundo, ele me convida e encontrá-lo lá. A comunicação se completa quando minha conduta encontra neste cominho seu próprio caminho. Há confirmação do outro por mim e de mim pelo outro. [...] É pelo meu corpo que compreendo o outro, como é pelo meu corpo que compreendo as coisas. $\mathrm{O}$ sentido do gesto assim compreendido não está por detrás dele, confunde-se com a estrutura do mundo que o gesto designa e que retomo à vontade, ele se abre no próprio gesto (MERLEAU-PONTY, 1971, p. 195-196).
}

Movimento, Porto Alegre, v. 15, n. 02, p. 187-210, abril/junho de 2009. 
Nesta mesma óptica, Merleau-Ponty (1971) comenta sobre a questão do hábito. Geralmente, pensamos que o corpo se habitua, ou seja, automatiza um movimento qualquer através de inúmeras tentativas e que, depois de automatizado, começa a agir cegamente, sem que precisassem pensar no movimento para que este execute um ato específico. $\mathrm{O}$ autor afirma o contrário, ele mostra que através do hábito, o corpo aprende e reflete e nunca poderá ser explicado como um ato puramente automático ou como sendo uma operação da inteligência. $\mathrm{O}$ autor cita a dança, em que comenta que o corpo capta e compreende o movimento que é a apreensão de uma significação motora. Pelo fato do corpo possuir o poder de aprender e refletir, ele não se restringe a situações que são fixadas para sempre. No hábito, podemos perceber que o corpo age sempre de forma préreflexiva inicialmente. Esta ação é independentemente das ordens que recebemos. A questão de aprender, neste sentido, não significa o potencial corporal de repetir o mesmo gesto inúmeras vezes, mas de proporcionar várias respostas a mesma situação motora.

Para Merleau-Ponty (1971), somos inseparáveis do mundo, na realidade, somos um ser-no-mundo. O hábito possui um potencial de ampliar nossa vivência neste mundo e até mesmo pode nos fazer mudar nossa forma de existência. O corpo se torna um campo aberto para todos os tipos de situações, sejam elas reais, virtuais, imaginárias e outras mais que não podemos identificar, por serem ínfimas, mas significativas. $\mathrm{O}$ corpo é que nos coloca em contato direto com o mundo e nos proporciona transformá-lo. Portanto, o corpo não pode ser comparado a um objeto físico, mas a uma "obra de arte. Num quadro ou num trecho de música, a ideia só pode ser comunicada pelo desdobramento das cores e dos sons" (MERLEAU-PONTY, 1971, p. 161). Mostrando assim a totalidade do corpo como expressão primordial das experiências vividas no mundo.

O homem sendo sua corporeidade se expressa de forma original, criativa e intencional. Este movimento expressivo é dirigido subjetivamente e intersubjetivamente para as coisas que habitam o mundo. Nesta relação de totalidade, em que não existe a possibilidade de pensar as partes em separado, o homem desvela todo o significado do mundo.

Movimento, Porto Alegre, v. 15, n. 02, p. 187-210, abril/junho de 2009. 


\section{CONSIDERAÇÕES FINAIS}

Esta intencionalidade do movimento humano habita todo o se movimentar, por se tratar de homens que se movimentam. Neste movimentar, o homem conhece o mundo à sua volta e se conhece a si mesmo. Dentro deste diálogo, ele identifica significações e o sentido das coisas e das outras pessoas. O movimento é uma forma de conhecimento que nos proporciona a identificação do significado do próprio movimento. As formas de movimentos não existem. A relação dialógica entre o homem e o mundo possibilita que este construa seus movimentos, que irão receber significações e sentidos apropriados para cada execução.

Os movimentos devem ser experimentados pelo executante através das suas sensações. Baseado na teoria da Gestalt ou na teoria da percepção, a estrutura do ser humano deve ser considerada. A subjetividade deve ser primordial na troca entre os seres humanos e o meio ambiente. Esta relação de totalidade entre homem e mundo é fundamental para a existência humana. O homem está para o mundo porque o mundo está para o homem. Esta reciprocidade intencional é o suporte essencial em direção ao entendimento do mundo e de todas as coisas que o habitam e suas respectivas relações. A visão fenomenológica busca ampliar o entendimento no movimento para além do empírico - analítico. Mostra que o movimento é uma relação entre as pessoas e o mundo. Com a fenomenologia o movimento tem que possuir significado e intencionalidade própria. A importância dada aqui ao movimento está no ser humano. Desta forma, a construção de movimentos é fundamental para que o aluno dê significações às suas ações e utilizem, para isto, a experimentação. O processo de aprendizagem deve se apresentar como um processo subjetivo, humano e aberto às experiências individuais.

A educação física como disciplina que faz parte do sistema educacional precisa de discussões que reflitam sobre sua prática. A questão do entendimento do movimento humano como totalidade é um assunto de grande relevância na atualidade. O caráter alienante e ideológico impregnado nos modernos meios de comunicação tecnologicamente desenvolvidos pelos avanços da ciência forma uma cortina

Movimento, Porto Alegre, v. 15, n. 02, p. 187-210, abril/junho de 2009. 
entre o ser humano e a realidade, tornando-o um mero objeto do sistema, dominado e sem vida. Esta forma de viver, instituído pelo mundo moderno da racionalidade científica, nos impede de sermos nós mesmos, criativo, autônomo, expressivo e possuidor de mundo.

Acreditamos que a educação física deve sofrer mudanças, para que seja entendida como disciplina pedagógica que valorize o ser humano. Esta mudança só pode acontecer através de uma nova compreensão de movimento humano. A visão atual limita o movimento humano em simples fenômeno da motricidade e um conjunto de articulações e de força. Precisamos ampliar esta visão do movimento humano e difundi-la. Ampliação esta que deve ser desenvolvida através de uma reflexão que relacione a educação física e o homem como unidade que se interagem. O exercício físico não é só físico e sim humano e neste humano se desvelam às experiências significantes, que buscam o real valor transmitido pelo movimento humano. Movimento que compreenda o mundo pela ação, mundo este entendido como sendo um mundo vivido por nós através de nossas experiências.

Para Freire (1981), o educando se apropria do conhecimento, quando ele o redescobre e o relaciona com o mundo vivido concreto. Desta forma, pode-se dizer que a verdadeira aprendizagem aconteceu. Sendo assim, temos que aproximar a realidade do mundo vivido ao mundo de movimento dos alunos. A educação física como educação, pretende agir sobre o homem e transformá-lo. Esta transformação só pode ser entendida mediante sua totalidade concreta. Neste sentido Kunz (1994) comenta que devemos ampliar as reflexões sobre o diálogo entre homem e mundo, enfatizando o se-movimentar como acontecimento fenomenológico, ou seja, relacionando de forma intencional as ações significativas e o que essas ações tenham como consequências educacionais para a vida. Neste sentido, o autor comenta que:

Não se trata de formar pessoas que se conheçam melhor, apenas, mas de formar gente consciente de que jamais conhecerá tudo de si, pois isso consiste em conhecer a humanidade e o mundo. É imprescindível que desencadeie um processo de conhecimento de si através dos valores humanos encontrados em cada individuo, possibilitando condições para que cada

Movimento, Porto Alegre, v. 15, n. 02, p. 187-210, abril/junho de 2009. 
aluno e aluna encontrem, por suas referências internas e não apenas do mundo exterior o dos outros, $\mathrm{o}$ que ele ou ela de fato são em relação ao mundo, aos outros e a si próprio. (KUNZ, 1994, p. 15)

The Phenomenology as the Embasement to the Significative Human Movement.

Abstract: Our work had as the main problematic, to investigate about the theoretical argumentation that the phenomenology proportions to the understanding of the human movement as significant. This theoretical and qualitative work had as basis Edmund Husserl's and Merleau Ponty's phenomenological thoughts. The phenomenological vision of the human movement proposes that the subject is his/her own movement author rather than just an object that receives orders to imitate patterns of pre-established movements. The movement must be understood as a dialogue between the human being and the world where the human being understands the world through the action. This dialogical movement is expressive and communicative which manifests itself in a creative gesture with the possibility to know and transform the world. This understanding of the human movement must orient the work in the Physical Education so that it can recuperate its real sense and meaning in the educational process.

Keywords: Phenomenology. Movement. Knowledge. Physical Education. 
La Fenomenología como Fundamentación a el Movimiento Humano Significativo

Resumen: Nuestro trabajo tenía como cañería problemática, investigar en la discusión teórica que el fenomenologia proporciona para el acuerdo del movimiento humano como significativo. Este trabajo teórico y cualitativo tenía como base que el fenomenológico pensó en Edmundo Husserl y Merleau Ponty. La visión del fenomenológica del movimiento humano considera que el ciudadano es el agente de su movimiento apropiado y no sólo de un objeto que reciba órdenes para imitar estándares de la precolocación del movimiento. El movimiento debe ser entendido como diálogo entre el hombre y el mundo, donde el ser humano entiende el mundo para la acción. Este movimiento del dialógico es expresivo y comunicativo que si es manifesto como gesto creativo, con la posibilidad para saber la transformación del mundo. Este acuerdo del movimiento humano debe dirigir el trabajo en la educación física, de modo que éste obtenga para recuperar su verdadero y significado sensibles en el proceso educativo.

Palabras clave: Fenomenologia. Movimiento. Conocimiento. Educación física.

\section{REFERÊNCIAS}

BELLO, A. A. Introdução à fenomenologia. Bauru: EDUSC, 2006.

BRACHT, V. Educação Física e ciência: cenas de um casamento (in)feliz. Íjui RS: UNIJUÍ, 1999.

CARMO, P. S. Merleau-Ponty: uma introdução. São Paulo: Editora EDUC, 2004.

CHAUÍ, M. Convite a filosofia. São Paulo SP: Ática, 1994.

DARTIGUES, A. O que é fenomenologia? 8. ed. São Paulo: Centauro, 2003.

CREMA, R. Introdução à visão holística. São Paulo: Summus, 1989.

FREIRE. P. Educação e mudança. 3. ed. São Paulo: Paz e Terra, 1981.

HUSSERL, E. A ideia da fenomenologia. São Paulo: Edições 70, 1986.

Meditações cartesianas. São Paulo: Madras, 2001.

Investigações lógicas: sexta investigação: elementos de uma elucidação fenomenológica do conhecimento. São Paulo: Nova Cultural, 1991.

JAPIASSÚ, H., MARCONDES, D. Dicionário básico de filosofia. 3. ed. rev e amp. Rio de Janeiro: Jorge Zahar, 1996.

Movimento, Porto Alegre, v. 15, n. 02, p. 187-210, abril/junho de 2009. 
JAPIASSU, H. As paixões da ciência: estudo de história das ciências. São Paulo: Letras e Letras, 1991.

KUNZ, E. Educação Física: ensino \& mudanças. ljuí: UNIJUI Editora, 1991.

Transformação didático: pedagógico do esporte. $3^{\mathrm{a}}$ ed. ljuí RS: Editora UNIJUI. $3^{\mathrm{a}}$ edição, 1994.

A relação teoria/prática no ensino/pesquisa da educação física. Motrivivência, Florianópolis, v. 7. n. 8, 1995.

MERLEAU-PONTY, M. Fenomenologia da percepção. São Paulo: Freitas Bastos, 1971.

SANTIN, S. Educação Física: uma abordagem filosófica da corporeidade. ljuí: UNIJUÍ, 1987.

Educação Física: temas pedagógicos. Porto Alegre: EST/ESEF, 1992.

Corporeidade. In: GONZÄLES, F. J., FENSTERSEIFER, P. E. (Org.). Dicionário crítico de Educação Física. ljuí: Editora Unijuí, 2005. p.103-104.

SCHWENGBER, M. S. V. Expressão Corporal. In: GONZÄLES, F. J., FENSTERSEIFER, P. E.(Org.). Dicionário crítico de Educação Física. ljuí: Editora Unijuí, 2005.

SOKOLOWSKI, R. Introdução à fenomenologia. São Paulo: Edições Loiola, 2004.

VAZ, A. F. A filosofia na Educação Física: soltando as amarras e a capacidade de ser negatividade. In: (Org.) NETO, A. F., GOELLNER, S. V., BRACHT, V. As ciências do Esporte no Brasil. Campinas: Autores associados, 1995.

Recebido em: 06.03.2008

Aprovado em: 16.02. 2009

Movimento, Porto Alegre, v. 15, n. 02, p. 187-210, abril/junho de 2009. 